\title{
Editorial
}

\section{Whiplash: Same Elephant, Different Room}

Musculoskeletal injury can cause acute pain and can also trigger chronic pain. The mechanisms resulting in these 2 outcomes are essentially different, with acute pain relating primarily to peripheral nociception and chronic pain relating primarily to central sensitization. Acute musculoskeletal pain usually resolves with time or treatment. Chronic pain, by definition, persists and associates with significant longterm health effects and diminished quality of life (QOL). Despite the importance of this problem, the issues surrounding persisting pain after injury remain controversial $^{1}$. Aspects of postinjury pain and disability are addressed in this issue of The Journal through followup of persons involved in minor trauma from motor vehicle accidents $^{2}$.

The clinical features of patients with persisting pain after trauma, where the inciting lesion has resolved, are usually distinctive and embody a number of characteristic pain phenotypes. Central sensitization is the most prominent contributing mechanism ${ }^{3}$. Common examples are fibromyalgia (FM), regional pain syndrome, and complex regional pain syndrome (CRPS $)^{4}$. These disorders are characterized by widespread or regionalized pain in a distribution that cannot be explained by an abnormality of a specific localized musculoskeletal or neural structure, be it in the periphery or in the spinal area. The pain may be segmental and often accompanied by unpleasant non-neuroanatomical sensory sensations within the same region. There is widespread or regional lowering of pain threshold elicited clinically by the determination of abnormal tenderness on palpation, more prominent in selected areas known as tender points. Muscular tightness, co-contraction, and development of trigger points are common. There is often mild soft tissue swelling and dermatographia, indicative of neurogenic inflammation. In CRPS more prominent vasomotor, sudomotor, muscle, and dystrophic features are present ${ }^{5}$.

In addition to these physical signs, patients complain to a varying degree about sleep disturbance, fatigue,

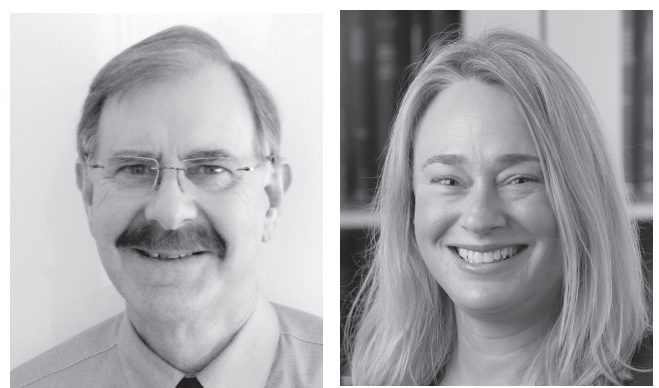

cognitive dysfunction, and somatic problems such as headache or gastrointestinal discomfort, and depression. Identification of these overarching symptoms, common to many chronic pain phenotypes, allowed for evolution of the criteria for FM. The initial 1990 American College of Rheumatology (ACR) classification criteria link widespread pain and widespread tenderness as core features ${ }^{6}$. The 2010/11 ACR diagnostic criteria draw on clinical features that associate the distribution of pain to high levels of the above key symptoms, particularly those that relate to sleep, fatigue, and cognition ${ }^{7}$. These symptoms provide a valid surrogate for emotional distress, and allow for development of the polysymptomatic distress scale (PSD) ${ }^{8}$. These criteria then are more holistic, recording more mind-body associations than pure clinical physical characteristics and generate a diagnosis of FM and also a specified point on the PSD scale continuum - higher levels associating with tendency to FM (so-called fibromyalgianess, or central sensitivity). These ACR criteria sets for FM are not mutually exclusive as one derives from the other, but they usefully capture different aspects of the FM phenotype. Importantly, because there is no absolute requirement for the pain to be widespread, the 2010/2011 criteria allow for diagnosis of many regional pain syndromes as FM.

In the context of postinjury chronic pain, the 2010/11 ACR criteria are clinically useful in that they represent the essence of central ongoing symptoms in a wide range of situations that have traditionally been designated with poorly considered specific terms. Whiplash is a good example of this. The Quebec Task Force defined whiplash as the initial "injury" and whiplash associated disorder (WAD) as the compilation of symptoms and signs that might follow over a longer time period after the initial injury had seemed to resolve 9 . The term "whiplash" derives from a putative mechanism of injury but should be discarded for a simple descriptive term, such as neck pain. This avoids potential iatrogenic consequences of the

See Health and QOL after mild whiplash injury, page 528

Personal non-commercial use only. The Journal of Rheumatology Copyright @ 2014 . All rights reserved. 
emotion-laden term "whiplash." The term WAD is even more problematic. Essentially, if one uses the 2010/11 ACR criteria, patients with WAD will either fulfill criteria for FM or have high PSD (fibromyalgianess) scores. There is no formal study of the PSD scale in WAD to date. However, to support this notion, a number of studies of patients who are considered to have WAD have found psychophysical characteristics typical of patients deemed to have $\mathrm{FM}^{10,11,12,13,14,15,16}$

This situation is similar to other regional pain syndromes that might occur after injury, such as low back pain and the various names for postinjury upper limb pain syndromes. Does it matter to re-label these disorders from the current contemporary named condition to another, namely FM? We believe that it does. It matters in that the FM central sensitization mechanism is well characterized and there is significant literature about how to best manage that disorder ${ }^{17}$. It brings these apparently different pain phenotypes back under the one umbrella, enhancing understanding, research, and patient care.

The causes and outcomes of injury-triggered chronic pain syndromes, such as FM, are of great interest owing to high patient morbidity and the important role of causality in the eyes of the law. Causality brings to the patient a range of issues including possible compensation and monetary reward, vindication, retribution, and blame. Being a victim of injury can result in loss of control, rumination, anger, and a host of other psychological responses. Taken together these factors may continue to feed the mechanisms of central sensitization. To gain better understanding of these complex and interacting factors, the study of well-defined triggers of FM should aid our understanding of this process. The onset of pain in the cervical region after a specific event such as a motor vehicle accident, with persisting pain in a significant proportion of patients thereafter, is an excellent model to study.

In this issue, Hours, et $a l^{2}$ use a French road accident trauma registry of 1168 adults to identify a representative cohort of 548 adults who were rated as having a mild injury on the Abbreviated Injury Scale classification ${ }^{18}$. Of these, $68 \%$ of 255 adults who sustained "whiplash injury" were compared to $70 \%$ of a reference group of 293 adults with soft-tissue injury of a similar severity in some other area of the body. Those with significant cervical spine lesions were excluded from the study. Predictive modeling was used to define which factors associated with different levels of health status, family, and occupational consequences and QOL 1 year after the initial accident.

The subsequent development of posttraumatic stress disorder (PTSD) was a strong predictor of outcome in both the whiplash and contusion groups. In fact, impaired QOL did not correlate with whiplash when models were adjusted for sociodemographic variables and history of psychological distress. PTSD was the main determining factor for poorer
QOL. Importantly, the initial injury was not a determinant in the 12-month outcome.

There are a number of caveats to this study. These relate to the specificity of the initial diagnosis and the classification that is done around the time of the incident. Questionnaires applied in this instance are highly selective and often do not capture the whole range of potentially important psychological factors that could contribute to the QOL and other outcome measures. Nevertheless, information gained in this study aids understanding. The data highlight the importance of the psychological reaction to a specific event, more than the actual event itself.

A high percentage of patients with FM have their condition triggered by a specific traumatic life factor ${ }^{19}$. There is a strong link between distress after trauma and pain. Up to $80 \%$ of patients with severe PTSD have chronic pain $^{20}$. Studies using 1990 ACR criteria note that trauma-associated distress links to $\mathrm{FM}^{21}$. It is likely that future studies using the 2010/2011 ACR diagnostic criteria and the PSD scale will identify a large population of patients with "WAD," as well as other regional pain syndromes, as having FM or high levels of fibromyalgianess or central sensitivity. Using this approach, it is hoped that the links between trauma, distress, and FM will be easier to define.

Once FM is triggered, the pain mechanisms involved are independent of those of the initial injury. This can cause mismanagement if the ongoing symptoms are treated as those of a peripheral injury, rather than relating to the central mechanisms driving FM. As the management is essentially different, so will the outcome be fundamentally different if FM is not recognized. The correct diagnosis of the ongoing symptoms will therefore affect a host of downstream events ranging from pain, disability, and emotional distress, through to interaction with social safety nets and litigation. Each of these may in turn create further distress and compound the problem.

The most important thing is to get the diagnosis right. The central sensitization mechanism characterizing FM is the "elephant in the room" in postinjury chronic pain, just as it is in a host of other medical conditions where pain and distress are present ${ }^{22}$. Poor appreciation of this ubiquitous human response to stress with its resultant characteristic pain phenotype will lead to poor management and bad and costly outcomes.

GEOFFREY OWEN LITTLEJOHN, MPH, MD, FRACP, Professor of Medicine, Emeritus Director, Rheumatology, Monash University and Monash Health; EMMA K. GUYMER, MBBS, FRACP,

Lecturer, Head of Fibromyalgia Clinic, Monash University and Monash Health, Clayton, Australia.

Address correspondence to Dr. Littlejohn, Suite H, Monash Medical Centre, 246 Clayton Road, Clayton, Victoria, Australia;

E-mail: Geoff.littlejohn@monash.edu

Personal non-commercial use only. The Journal of Rheumatology Copyright @ 2014 . All rights reserved. 


\section{REFERENCES}

1. Hadler NM. Workers' compensation, fibromyalgia, and kafka. J Rheumatol 2013;40:216-8.

2. Hours M, Khati I, Charnay P, Chossegros L, Tardy H, Tournier C, et al. One year after mild injury: comparison of health status and quality of life in victims of whiplash versus other injuries. J Rheumatol 2014;41:528-38.

3. Phillips K, Clauw DJ. Central pain mechanisms in chronic pain states - maybe it is all in their head. Best Prac Res Clin Rheumatol 2011;25:141-54

4. Littlejohn G. Regional pain syndrome: clinical characteristics, mechanisms and management. Nat Clin Prac Rheumatol 2007;3:504-11.

5. Harden RN, Oaklander AL, Burton AW, Perez RS, Richardson K, Swan M, et al. Complex regional pain syndrome: practical diagnostic and treatment guidelines, 4th ed. Pain Med 2013; 14:180-229.

6. Wolfe F, Smythe HA, Yunus MB, Bennett RM, Bombardier C, Goldenberg DL, et al. The American College of Rheumatology 1990 criteria for the classification of fibromyalgia. Report of the Multicenter Criteria Committee. Arthritis Rheum 1990;33:160-72.

7. Wolfe F, Clauw DJ, Fitzcharles MA, Goldenberg DL, Häuser W, Katz RS, et al. Fibromyalgia criteria and severity scales for clinical and epidemiological studies: a modification of the ACR Preliminary Diagnostic Criteria for Fibromyalgia. J Rheumatol 2011;38:1113-22.

8. Wolfe F. New American College of Rheumatology criteria for fibromyalgia: a twenty-year journey. Arthritis Care Res 2010;62:583-4.

9. Spitzer WO, Skovron ML, Salmi LR, Cassidy JD, Duranceau J, Suissa S, et al. Scientific monograph of the Quebec Task Force on Whiplash-Associated Disorders: redefining "whiplash" and its management. Spine 1995;20:1S-73S

10. Curatolo M, Petersen-Felix S, Arendt-Nielsen L, Giani C, Zbinden AM, Radanov BP. Central hypersensitivity in chronic pain after whiplash injury. Clin J Pain 2001;17:306-15.

11. Koelbaek Johansen M, Graven-Nielsen T, Schou Olesen A, Arendt-Nielsen L. Generalised muscular hyperalgesia in chronic whiplash syndrome. Pain 1999;83:229-34.
12. Sterling M, Jull G, Vicenzino B, Kenardy J. Sensory hypersensitivity occurs soon after whiplash injury and is associated with poor recovery. Pain 2003;104:509-17.

13. Banic B, Petersen-Felix S, Andersen OK, Radanov BP, Villiger PM, Arendt-Nielsen L, et al. Evidence for spinal cord hypersensitivity in chronic pain after whiplash injury and in fibromyalgia. Pain 2004;107:7-15.

14. Sterling M, Hodkinson E, Pettiford C, Souvlis T, Curatolo M. Psychologic factors are related to some sensory pain thresholds but not nociceptive flexion reflex threshold in chronic whiplash. Clin J Pain 2008;24:124-30.

15. Myrtveit SM, Wilhelmsen I, Petrie KJ, Skogen JC, Sivertsen B. What characterizes individuals developing chronic whiplash?: The Nord-Trondelag Health Study (HUNT). J Psychosom Res 2013;74:393-400.

16. Lemming D, Graven-Nielsen T, Sorensen J, Arendt-Nielsen L, Gerdle B. Widespread pain hypersensitivity and facilitated temporal summation of deep tissue pain in whiplash associated disorder: an explorative study of women. J Rehab Med 2012;44:648-57.

17. Yunus MB. The prevalence of fibromyalgia in other chronic pain conditions. Pain Res Treat 2012;2012:584573.

18. The abbreviated injury scale-1990 Revision (AIS-90). Des Plains, IL: Association for the Advancement of Automotive Medicine; 1990.

19. Buskila D, Mader R. Trauma and work-related pain syndromes: risk factors, clinical picture, insurance and law interventions. Best Prac Res Clin Rheumatol 2011;25:199-207.

20. Egloff N, Hirschi A, von Kanel R. Traumatization and chronic pain: a further model of interaction. J Pain Res 2013;6:765-70.

21. Hauser W, Galek A, Erbsloh-Moller B, Köllner V, Kühn-Becker H, Langhorst J, et al. Posttraumatic stress disorder in fibromyalgia syndrome: prevalence, temporal relationship between posttraumatic stress and fibromyalgia symptoms, and impact on clinical outcome. Pain 2013;154:1216-23.

22. Atzeni F, Cazzola M, Benucci M, Di Franco M, Salaffi F, Sarzi-Puttini P. Chronic widespread pain in the spectrum of rheumatological diseases. Best Prac Res Clin Rheumatol 2011;25:165-71.

J Rheumatol 2014;41:411-13; doi:10.3899/jrheum.131541 